\title{
LOS BIENES RAÍCES DE LOS MORISCOS EXPULSADOS
}

\author{
Jorge Gil Herrera*
}

“...todavía usando de clemencia con ellos, tengo por bien que puedan durante el tiempo de 30 días, disponer de sus bienes muebles y semovientes y llevarlos no en oro, plata, ni joyas, ni letras de cambio, sino en mercadurías no prohibidas, compradas a los naturales destos reynos..., porque los rayces han de quedar por hacienda mía, para aplicarla a buenas obras del servicio de Dios nuestro Señor..."

Tanto en el bando de expulsión de los moriscos de Andalucía como en el promulgado para los moriscos de Castilla se exponía claramente cuáles eran las intenciones de la monarquía con respecto a los bienes raíces de los moriscos. A pesar del importante número de trabajos publicados y sus diferentes planteamientos a la hora de abordar la cuestión morisca, sobre todo durante este último año del centenario, hay que señalar que son pocos los trabajos que se han interesado por el aspecto económico de la expulsión o simplemente en estudios de tipo socio-económico de la minoría. Este enfoque, el socio-económico, fue transitado durante los años 90 por los estudios locales, en los que se intentaba hacer hablar a fuentes notariales en contraposición de las llamadas estatales, fuentes que para muchos de estos autores estaban "envenenadas" ${ }^{2}$. La expulsión, una vez más y como punto de inflexión en la historia de la minoría, nos permite aproximarnos a la economía morisca gracias al tipo de documentación producida por el Consejo de Hacienda y su Contaduría Mayor, que tras la expulsión tuvieron la tarea de administrar los bienes raíces de los moriscos. La confiscación, tasación, administración, venta y alquiler de dichos bienes, se encomendaron al Consejo de Hacienda, que pretendió desde los primeros

\footnotetext{
* E.H.E.S.S. París.

1. Biblioteca Nacional de Madrid, en adelante BNM, VE-36-4 (Córdoba, 17-1-1610).

2. G. COLÁS LATORRE, «Los moriscos aragoneses: una definición más allá de la religión y la política», Sharq Al-Andalus, 12, Alicante, 1995, pp. 147-161; el autor nos dice que se "ha otorgado a los papeles 'estatales' e inquisitoriales una credibilidad que nunca se debió conceder". Ver también, «Cristianos y moriscos en Aragón: una nueva lectura de sus relaciones y comportamientos en el marco de la sociedad rural», Mélanges de la Casa de Velázquez, 29 (2), 1993. A. GARCÍA PEDRAZA, «El otro morisco: algunas reflexiones sobre el estudio de su religiosidad a través de fuentes notariales», Sharq al-Andalus, 12, 1995, pp. 223-234. Para estudios sobre comunidades locales más relevantes encontramos a S. TAPIA SÁNCHEZ, La comunidad morisca de Ávila, Salamanca, 1991. J. ARANDA DONCEL, Los moriscos en tierras de Córdoba, Córdoba, 1984.
} 
momentos realizar su función con una escrupulosa gestión, intentando que todo lo que perteneciese a los moriscos revirtiera de forma rápida y eficaz en las necesidades económicas que la monarquía tenía en aquellos momentos. Para ello desplegó los medios necesarios y ambicionó la puesta en práctica de un ideario sobre cómo se debía realizar dicha gestión en cada una de las partes del territorio, pretendiendo con ello una transparencia y solvencia que no siempre se alcanzaron, pero que sí generó una documentación más o menos concreta de la cantidad de bienes raíces que poseían los moriscos en el momento de su expulsión. En cualquier caso, el ímpetu y rigor con el que se pretendió realizar la gestión de los bienes raíces de los moriscos provocó una inmensa documentación, a la que hoy debemos enfrentarnos si realmente deseamos conocer el patrimonio atesorado por los moriscos durante su presencia en España. No debemos olvidar que la cuestión económica fue uno de los argumentos utilizados para pedir o defender la permanencia de los moriscos ${ }^{3}$.

Esta documentación, a pesar de sus limitaciones, puede tener un valor añadido para los estudios a nivel local, ya que están registradas gran parte de las ventas en cada una de las localidades donde había bienes de moriscos, indicando en la mayoría de los casos el comprador, a quién pertenecía la casa e incluso las pujas que realizaron los potenciales compradores y una pequeña descripción del bien subastado.

En este artículo, en el que sólo se presentarán los primeros resultados de una investigación más amplia, se expondrá la cuantificación del valor de los bienes raíces que la monarquía realizó poco después de que los moriscos salieran de su lugar de origen. El marco geográfico de este estudio engloba toda la Corona de Castilla porque en la Corona de Aragón, sobre todo en el Reino de Valencia, pasaron a posesión de los señores de moriscos ${ }^{4}$, por lo que no ha dejado rastro en la documentación del Consejo de Hacienda, fuente documental principal de nuestro estudio. Teniendo en cuenta que la administración de dichos bienes duró más de un siglo, ya que algunos de los bienes siguieron dando algún tipo de rédito a la Corona hasta finales del siglo XVII, nos hemos limitado a ver cómo se organizó y se tasaron los bienes de moriscos en el momento de su expulsión, sin adentrarnos en la venta o explotación de dichos bienes.

3. P. BORONAT Y BARRACHINA, Los moriscos españoles y su expulsión, Granada, Universidad de Granada, 1992 (edición facsímil de la de 1902), pp. 37-38. En otros documentos destacamos el segundo memorial que el Patriarca Ribera envió a Felipe III en 1602, en el que defiende la permanencia de los moriscos de Valencia por su importancia económica y pretende al mismo tiempo impulsar la expulsión de los moriscos de Castilla por lo perjudiciales que eran para la economía del reino. El texto está publicado por M. GuAdalajara XaVIER, Memorable expulsión y iustisimo destierro de los moriscos de España, Pamplona, Nicolás de Assiayn, 1613, fols. 82-86. Ver J. GIL HERRERA, «El primer intento de expulsión de los moriscos durante el reinado de Felipe III", en prensa (Coloquio dirigido por B. Vincent “L'expulsion des morisques. Quand? Pourquoi? Comment?", realizado entre 2-4 julio de 2009 en París).

4. En Castilla los bienes que eran de régimen señorial tampoco pudo confiscarlos la monarquía. 


\section{LA EXPULSIÓN EN TORNO A LOS BIENES RAÍCES DE MORISCOS}

Para poder comprender hasta qué punto los cuadros que se ofrecerán a continuación tienen total validez y se ajustan bastante al cómputo final, resulta imprescindible exponer de forma sintética los acontecimientos más importantes que rodearon la expulsión de los moriscos de Castilla, Andalucía y Murcia.

El momento en el que el presidente de la Hacienda, Fernando Carrillo ${ }^{5}$, envió el primer informe sobre las tasaciones de los bienes raíces a Felipe III, en abril de 1611, ya apenas quedaban moriscos en Castilla, Andalucía, Extremadura y Murcia, y gran parte de los que quedaron tendrán la oportunidad de vender sus bienes inmuebles antes de partir ${ }^{6}$.

Una vez concluida la expulsión de los moriscos valencianos, la monarquía de Felipe III decide que los siguientes en ser expelidos serían los andaluces y los murcianos, al tiempo que se les daba libertad a los moriscos castellanos para que aquél que quisiera irse pudiera hacerlo sin ningún impedimento. Firmado el decreto de salida libre para los moriscos castellanos el 28 de diciembre de 1609 y promulgado el bando el 2 de enero de 1610, se exhortaba a los moriscos que se sintiesen incómodos en Castilla a tomar el camino del exilio, bajo la condición de que lo hiciesen en dirección a Francia -para no interferir con la expulsión organizada de los moriscos andaluces y murcianos programada para mediados del mes de enero-, y debían dejar sus bienes raíces llevando sólo consigo mercadurías no prohibidas.

Esta libertad otorgada a los moriscos castellanos para salir por Francia era la plasmación en decreto de una práctica habitual, ya que era el camino que muchos moriscos habían utilizado en los años precedentes a la expulsión y que se mantuvo durante la deportación de los valencianos. La monarquía era consciente de estas huidas e incapaz de ponerles freno, y de alguna manera fue una situación que se había permitido al menos desde un año antes, como lo demuestra la consulta del Consejo de Estado de junio de 1608, que tras haber recibido frecuentes avisos de salida de moriscos por la frontera pirenaica ${ }^{7}$, se da

5. Archivo General de Simancas (en adelante AGS), Consejo y Juntas de Hacienda (en adelante CJH), Legajo (en adelante Leg.) 503-9-1. “Dos géneros de hacienda ay de los moriscos, una los bienes raíces que dexaron, y otra las mitades que an dado del dinero y joyas que an registrado por que se les permitiese sacar de estos reynos la otra mitad".

6. Quedaban fundamentalmente los llamados "antiguos" o "mudéjares", que como veremos a continuación se les permitirá vender los bienes raíces que tenían.

7. L.F. Bernabé PONS y J. GIL HeRRERA, «Los moriscos fuera de España: rutas y financiación», en prensa (Congreso Internacional Los Moriscos. La expulsión y después. Dirigido por Mercedes García Arenal. Madrid, 3 y 4 septiembre, 2009). L.F. BERNABÉ PONS, «Notas para la cohesión de la comunidad morisca más allá de su expulsión de España», Al-Qanțara, XXIX, 2, 2008, pp. 307332. Ver también L.F. BERNABÉ PONS, «Las migraciones moriscas al Magreb: balance bibliográfico y perspectivas», en A.I. Planet y F. RAMOS (coords.), Relaciones Hispano-Marroquíes: Una vecindad en construcción, Madrid, 2006, pp. 63-100. 
orden al virrey de Cataluña para que hiciese la vista gorda y permitiese pasar al otro lado de los Pirineos todo aquél que emprendiese el camino del destierro, sobre todo si eran pobres ${ }^{8}$. Sabemos que las autoridades aragonesas poco podían hacer para impedirles el paso hacia Francia, ya que el tránsito a un reino cristiano no suponía riesgo alguno para los moriscos, sobre todo si estos procedían del reino de Aragón, ya que no incurrían en ningún delito y no estaba castigado por la ley, siempre y cuando no llevaran mercaderías prohibidas, y no se hiciera para espiar o para renegar de la fe cristiana 9 .

Dos hechos pudieron acelerar el flujo de salida y el destierro de los moriscos castellanos propiciando el decreto de salida voluntaria. El desalojo de los moriscos de Madrid en la primavera de 1609 y el comienzo de la expulsión en Valencia en septiembre de ese mismo año, hicieron pensar a muchos de los moriscos castellanos que pronto sería su turno, lo que propició un mayor número de salidas vía Francia ${ }^{10}$. El 14 de noviembre de 1609 la monarquía se vio obligada a dar orden para que los moriscos no pudieran vender sus bienes raíces, algo que era práctica habitual e indicaba que estaban ultimando los preparativos para irse ${ }^{11}$. La inquietud de la monarquía en esos momentos era que con estas ventas se le estaba privando del botín tras la expulsión, algo que no estaba dispuesta a consentir y que propició una serie de órdenes para contro-

8. AGS, Estado (en adelante Est.), Leg. 2025, doc. 119. Carta del comendador de León al virrey de Cataluña, el duque de Monteleón, en el que le dice que "si entendiese que entre los moriscos que pasaran por aquella frontera, haviere algunos ricos y que sean cavezas de los otros eche mano dellos, y avise de los que fueren y de que partes son pero con los que no fueren desta calidad sino que sea gente común disimule con ellos pues quantos menos hubiere será lo mejor".

9. AGS, Guerra Antigua (en adelante GA), Leg. 706 y 720. En esos momentos el maestre de Jaca tenía retenidos a varios de ellos y le recordaba al rey en carta del 29 de diciembre de 1608 que los moriscos de Aragón podían pasar a Francia libremente: "aunque nos a mas que avellos prendidos es contra fuero porque los deste reyno proyben todo genero distorsión o castigo a los que quieran pasar al de Francia". Además se ve en la imposibilidad de continuar los interrogatorios, tal como escribe el virrey de Aragón al rey, ya que no puede torturarles: "los que están en el Castillo de Jaca detenidos los estarán hasta ver los que V. Mag. mandara que se haga porque por la vía ordinaria no pueden ser castigados en este Reyno, ni hacerse con libertad las diligencias necesarias para apurar la verdad, y si por ser castellanos se pudiesen, sin hacer ruido, en este reyno pasar al de Castilla, lo tendría por acertado porque ahí podría $\mathrm{V}$ Mag. mejor mandar averiguar los fines de esta gente...".

10. Hay innumerables avisos de salida durante los años 1608 y 1609. El más significativo es el dado por el corregidor de Toledo el 30 de octubre de 1609, donde indica que de los 1.747 vecinos que estaban censados en 1598 sólo quedaban 989 vecinos. Mirar también AGS, GA, Leg. 721.

11. M. Guadalajara Xavier, op. cit., p. 27 ro. También en F. Janer, Condición social de los moriscos de España, Barcelona, Alta Fulla, 1987 (fascímil de la de Madrid de 1857) p. 339. "en todas partes van los moriscos vendiendo sus haziendas, assí las rayzes, como los bienes muebles y semimoviente... hagays pregonar en todos los lugares de vuestro distrito que ningún morisco sea osado de vender sus bienes rayzes, so pena de perdimiento de todos sus bienes, y la misma pena mando tenga qualquier christiano viejo, o persona, que comprare...". También existe un número importante de avisos en distintos legajos de Estado y Consejo y Junta de Hacienda. 
lar y prohibir dichas ventas ${ }^{12}$. Para controlar los bienes raíces que los moriscos estaban dejando, y evitar ventas fraudulentas, la monarquía distribuyó a trece jueces en ámbitos geográficos concretos para su administración y venta. La orden se cursó a principios de marzo de 1610 y los jueces tenían instrucciones precisas de cómo habían de inventariar y tasar dichos bienes ${ }^{13}$.

Entre tanto los moriscos continuaban con la evasión de riqueza del reino, lo que propició una medida controvertida que supuso una vía de recaudación importante para las arcas reales. El 17 de febrero de 1610, tras haber prorrogado por dos veces la permisión de salida de los moriscos de Castilla, el rey va a permitir a los moriscos que puedan sacar la mitad del dinero, oro, plata y joyas que declarasen. Es decir, se va aplicar una medida que contravenía las ordenanzas del reino y la lógica económica del momento y que sólo se puede explicar por la incapacidad de controlar la fuga de capital que se venía realizando de forma ilegal ${ }^{14}$.

Por suspicacias y desconfianzas a la instalación o paso de moriscos por Francia, a finales de marzo se cierra oficialmente la frontera pirenaica y se establece el puerto de Cartagena -ya acababa la expulsión de los granadinos de Murcia- como nuevo punto de salida para los moriscos castellanos ${ }^{15}$. A mediados de abril comienzan a llegar los primeros grupos a Cartagena, donde ya existía una aduana para recoger las mitades de los moriscos granadinos residentes en Murcia. El 10 de julio de 1610 se firmó el decreto de expulsión por el cual se obligaba a todos los moriscos de Castilla a abandonar España. Los puntos de salida serían el puerto de Cartagena, y a petición y demanda de muchos moriscos de Castilla la Vieja se volvía a abrir la frontera pirenaica en agosto ${ }^{16}$, estableciendo la aduana en Vitoria y punto de recogida de los "pasaportes" en Behobia.

A finales de 1610 la expulsión se estancó a causa de una infinidad de pleitos interpuestos por los moriscos, lo que lleva al conde de Salazar, comi-

12. AGS, Contaduría General (en adelante CG), Leg. 3025. Orden que se volvería a repetir el 14 de febrero, en el que se instaba a los justicias que informaran de las ventas y cesiones que se habían producido desde entonces que eran ilegales. En distintos legajos de las Contadurías podemos encontrar listas de cesiones y ventas ilegales.

13. AGS, CG, Leg. 3025.

14. J. Gil Herrera, «El Botín de la Expulsión. Proceso de recaudación de las mitades y tasación de los bienes raíces de los moriscos de Castilla», Chronica Nova, 2010, en prensa. El dinero recaudado por este concepto, de las mitades, ascendió a más de 120 millones de maravedíes.

15. AGS, Est., Leg. 228-2. Carta de Sancho Bravo sobre el inconveniente de los moriscos que pasen a Francia. El conde de Salazar envió una carta con una relación de los que por allí habían pasado: 8.724 moriscos, que eran 1.701 casas, que en ese momento había en Burgos unos 800 de Toledo y aguardaban muy cerca de Burgos unos 4.000 moriscos más.

16. P. SANTONI, «Le passage des morisques en Provence», Provence historique, Fascicule 185, 1996 pp. 342-379. El 22 de febrero Enrique IV concedió entrada libre a los moriscos. Hay que decir que los primeros en pasar a Francia fueron ricos, y esto ayudó a que en los primeros momentos se viera con buenos ojos la llegada de moriscos. El 15 de abril ya había comisarios asignados para organizar el flujo y conducir a los moriscos hacia los puertos. 
sario de la empresa, a enviar una relación de los moriscos que quedaban en el reino. En enero de 1611, según los datos ofrecidos por dicha relación, quedaban en Castilla 1.500 familias, 744 de ellas eran de los llamados mudéjares. Para favorecer la expulsión y desatascar el problema de los pleitos, el 22 de mayo de 1611 se decreta una nueva prórroga del bando de expulsión hasta mediados de junio y, sorprendentemente, se dispone que "durante este periodo [los moriscos] dispongan de la hacienda en virtud de la permisión que para esto se les ha dado últimamente advirtiendo que no se le ha de conceder más tiempo y que si no acabara lo que tuvieren que hacer en materia de sus haciendas no por esto dejaran de ser expelidos, quedando uno por otros para fenecer lo dejaren...". En este sentido contamos con el caso estudiado por Olatz Villanueva para los moriscos de Valladolid, donde nos ilustra con varios casos extraídos del archivo de la Chancillería: "los moriscos granadinos habían recibido permiso Real para que los moriscos del Reino de Granada también puedan vender sus bienes raíces como los moriscos viejos de Valladolid" ${ }^{\prime 17}$. Una vez terminado el plazo de expulsión se le dio permiso a algunos miembros de la comunidad morisca para terminar de vender los dichos bienes raíces.

Para terminar este apartado habría que añadir que al otro grupo importante de moriscos que aún quedaban por expulsar, los moriscos del valle de Ricote, también se les dio permiso para poder vender sus bienes raíces.

\section{LAS COMISIONES PARA LA ADMINISTRACIÓN DE LOS BIENES RAÍCES}

El 5 de marzo se firmaron las comisiones para que los trece jueces comisarios fueran a los lugares que les habían sido asignados para recoger los primeros informes elaborados por los justicias, y continuar con el inventario y tasación de los bienes. El 29 de mayo de 1610, para evitar el deterioro progresivo de los bienes, se les dio comisión para que comenzaran la venta de bienes raíces de los lugares de realengo que debían realizar según una serie de instrucciones confeccionadas para tal efecto.

Estas instrucciones han sido objeto de estudio por parte de F.J. Moreno Díaz del Campo, por lo que sólo mencionaremos algunos de los apartados más relevantes ${ }^{18}$ :

17. O. Villanueva Zubizarreta, «Camino de Berbería. El exilio forzoso de los moriscos vallisoletanos en 1610», Instituto de Historia, 26, 2006, pp. 61-80.

18. F.J. MORENO DíAz DEL CAMPO, «Geografía de la expulsión morisca. Aproximación al análisis de la administración y venta del patrimonio de los moriscos expulsados de la Corona de Castilla», Chronica Nova, 31, 2005, pp. 379-426. 
1. Los bienes raíces que la monarquía consideraba que podían ser confiscados eran aquellos que se encontraban en tierras de "realengo, ordenes y behetrías, como en señoríos que no fuesen de solariego", es decir -y según entendemos solariego-, no se confiscarían aquellos bienes raíces que estuvieran en régimen de señorío territorial.

2. Debían ser inventariados y tasados los bienes frutos que los moriscos hubieran dejado, además del inmobiliario en casas, heredades, molinos, colmenares, jabonerías o bodegas.

3. Para inventariar y tasar, el juez de la comisión debía de valerse de personas expertas que fueran nombradas y reconocidas por los cabildos o ayuntamientos de cada lugar. Contarían con una serie de comisarios de confianza nombrados por dicho juez que recorrerían el territorio asignado supervisando dicha tarea. Además, en cada localidad se nombraría a fieles que fueran aprobados por los cabildos o ayuntamientos, y debían ser preferentemente personas hacendadas, ya que serían los encargados de recaudar el dinero de las ventas.

4. La venta se realizaría en subasta pública, con los correspondientes pregones y fechas para las pujas y el remate final. En el pregón debían indicarse las cargas con las que la propiedad se vendía y, en cualquier caso, ya fueran de censos a quitar, perpetuos o cualquier tipo de "hipoteca especial o general", se venderían con la carga, lo que podía ser considerado a la hora de la venta para una reducción del precio. Si los bienes no excedían de 50 ducados no era necesario hacer pregón y se podrían vender al mejor postor.

5. No se podía vender por menos de lo tasado y se debía procurar que en la venta la mayor parte fuera al contado, y que las obligaciones no excedieran los dos años. Las escrituras de venta las tenía que otorgar el juez de la comisión y debían recoger el tamaño, los lindes o los censos.

6. Por último se indicaba que se podían vender los bienes confiscados en los lugares de señorío hasta nueva orden ${ }^{19}$.

Estas trece primeras comisiones que abarcaron todo el territorio tuvieron una vigencia de poco más de un año. Transcurrido dicho tiempo se renovaría o se volverían a nombrar nuevos comisarios para un ámbito territorial más pequeño. La multiplicación de comisarios se realizó con el fin de reducir costes, ya que los nuevos nombramientos recayeron en personas que ya desempeñaban algún oficio en las localidades asignadas, tales como los corregidores ${ }^{20}$. La relación de comisarios y fieles que se nombraron en los años sucesivos a la expulsión ha sido publicada por Moreno Díaz del Campo ${ }^{21}$.

19. AGS, CG, Leg. 3025.

20. Ibídem.

21. F.J. Moreno Díaz del CAMPo, op. cit. 
A la primera de las comisiones se les envió orden el 7 de abril de 1610 para que remitiesen una lista completa del inventario y tasación de los bienes raíces, orden que volvió a transmitirse meses más tarde debido al poco éxito de la primera demanda. Las listas comenzaron a llegar al Consejo y Juntas de Hacienda a principios de 1611. A partir de ese momento Antonio González Legarda confeccionó una relación que envió el 12 de febrero de 1611 al monarca, en la que daba cuenta de lo que hasta ese momento se había inventariado, tasado y vendido ${ }^{22}$.

Las listas de las tasaciones globales que a continuación se van a exponer corresponden a tres momentos diferentes, pero que se pueden complementar y dar un resultado bastante aproximado de la tasación final. Esto es debido a que muchos de los jueces no tuvieron las tasaciones en los momentos que se les pedía. Por otro lado, para los bienes de lugares de señorío que no fueron vendidos en un primer momento, a pesar de la insistencia del Consejo de Hacienda, se pidió una segunda tasación que fuera más completa, que fue confeccionada en agosto de 1612. También se han incluido las primeras ventas que realizaron en los lugares de realengo durante los primeros meses, concretamente hasta principio del invierno de 1610. La relación que se ofrece es por tanto la tasación global de los bienes de los moriscos, que corresponde a tres legajos y tres momentos diferentes. La primera tasación es la de los lugares de realengo enviada en febrero de 1611, que se encuentra en el legajo 503 de Consejo y Junta de Hacienda; la segunda, la de señorío, de agosto de 1612 se encuentra en el legajo 520; y una tercera que correspondería a los bienes de los moriscos de Andalucía.

\section{TASACIONES}

\section{Juez licenciado Francisco HernándeZ de SALCEDO}

La "Villa de Madrid y a las ciudades de Toledo y Guadalajara y villas y lugares de sus jurisdicciones tierras y partidos excepto a los lugares que de la tierra y partido de Guadalajara están comprendidas en otras comisiones, como luego se dará. Y así mismo se le mando fuese a todas las villas y lugares que hay desde Toledo hasta los puertos de Guadarrama y de Chinchón y villas de aquel estado".

\section{Lugares de realengo}

“En los lugares de realengo, descontados censos y deudas hasta el 24 de enero de 1611 estaba estimados los bienes raíces en 14.724.441 de maravedíes. Para Madrid los bienes se tasaron en 2.231 .675 y se habían vendido todos los bienes. En los Dos Carabancheles se vendieron todos los bienes que ascendían a

22. AGS, CJH, Leg. 503 9-6. 
205.736 maravedíes. En Bicalvaro se vendieron 75.479 mrs y en Fuenlabrada hay 2 casas que no se habían vendido y fueron tasadas en 105.000 maravedíes $^{\prime 23}$.

\section{Lugares de señorío ${ }^{24}$}

\begin{tabular}{|c|c|c|}
\hline LUGAR & SEÑOR & TASACIÓN \\
\hline Valdemoro & Duque de Lerma & 1.525 .480 \\
\hline Torrijos & Duque de Maqueda & 1.440 .048 \\
\hline Pelayos & Marqués de las Navas & 59.588 \\
\hline Santa Olalla & Conde de Orgaz & 133.750 \\
\hline Pastrana & Duque de Pastrana & 9.853 .352 \\
\hline La Puebla de Montalbán & Conde de Sella & 1.445 .302 \\
\hline Mondéjar & Marqués de Mondéjar & 1.268 .600 \\
\hline Alcalá & Arzobispo de Toledo & 3.385 .161 \\
\hline Torrejón de Velasco & Conde de Puñón Rostro & $710.000^{25}$ \\
\hline Chinchón & Conde de Chinchón & 2.083 .693 \\
\hline Mejorada & Francisco González de Heredia & 628.703 \\
\hline El Molar & Antonio de Eguino & 38.262 \\
\hline Bayona & Conde de Chinchón & 52.660 \\
\hline Curita & Duque de Pastrana & 30.350 \\
\hline Cienpozuelo & Conde de Chinchón & 156.152 \\
\hline Villafranca de Gaitán & Luis Gaytán & 149.540 \\
\hline Uceda & Duque de Uceda & 588.626 \\
\hline Rielves & Ciudad de Toledo & 13.600 \\
\hline Cogolludo & Duque de Medinaceli & 67.847 \\
\hline Pesadilla & Marqués de Cañete & 8.274 \\
\hline Salamanca & Conde de Villamar & 106.080 \\
\hline Lillo & Conde de Fuensalida y de Francisca Osorio & 7.700 \\
\hline Colmenar de Oreja & Luisa de Cárdenas & 1.690 .522 \\
\hline
\end{tabular}

23. AGS, CJH, 503-9-6. Todas las tasaciones sobre los lugares de realengo que a continuación se expondrán han sido tomadas de este legajo, excepto el caso de las comisiones que corresponde a los bienes de los moriscos de Andalucía, que será indicada en su momento.

24. AGS, CJH, 520-14-1-3. Las tasaciones sobre los lugares de señorío están extraídas de las segundas tasaciones realizadas en agosto de 1612. Las siguientes tasaciones sobre los bienes en lugares de señorío están extraídas de este mismo legajo, por lo que se omitirán las dichas notas al pie de página.

25. En AGS, CJH, 503-9-6. Existe una copia incompleta donde aparece la cifra de $310 \mathrm{mrs}$. 


\begin{tabular}{llr}
\hline LUGAR & SEÑOR & TASACIÓN \\
\hline Valdetorres & Francisco de Garnica & 144.608 \\
Aviñón & Marqués de Aviñón & 551.088 \\
Carabaca & Francisco de Santoyo & 30.500 \\
Tielmes & Conde de Villalonga & $133-686$ \\
Lugar del Pozo & Marqués de Mondéjar & 75.226 \\
Almoguera & Marqués de Mondéjar & 80.920 \\
Valdaracete & Duque de Pastrana & 277.000 \\
Estremera & Duque de Pastrana & 47.800 \\
Drieves & Marqués de Mondéjar & 11.220 \\
Escalona & Duque de Escalona & 1.296 .918 \\
Santa Orcaz & Arzobispo de Toledo & 41.500 \\
Navalcarnero & Conde de Casarubios & 59.160 \\
Quijorno & Conde de Chinchón & 81.546 \\
Alvalete de Zurita & Conde de Chinchón & 211.900 \\
Guiñon & Íñigo de Mendoza & $90.500^{26}$ \\
Yébenes & Ciudad de Toledo & $58.956^{27}$ \\
Ontanarejo & Ciudad de Toledo & $63.050^{28}$ \\
\hline TOTAL & & $29.130 .026^{29}$ \\
\hline & &
\end{tabular}

\section{COMisión AL JUEZ Andrés de ARANDA}

"Tuvo comisión para todas las ciudades, villas y lugares de la Mancha y obispados de Cuenca, Sigüenza, Ocaña y villas y lugares de su gobernación".

\section{Lugares de realengo}

“Según las relaciones enviadas suman 39.925.287 maravedíes, sin sacar los censos y deudas y como no se ha podido averiguar y le parece que deben ser una cuarta parte, por lo que al final deben quedar 29.945.368 maravedíes".

26. En la relación enviada en febrero de 1611 que se encuentra en AGS, CJH, 503-9-6 aparece este señorío, no aparece en el segundo mandado del 18 de agosto de 1612 que es el último y más completo.

27. Igual que el precedente, sólo aparece en la primera relación.

28. Igual que el precedente.

29. El total una vez sumado todos los señoríos, incluidos los que no aparecen en el documento. En el original aparece la cifra de $28.917 .520 \mathrm{mrs}$. 
Bienes de Ocaña y otros 22 lugares

\begin{tabular}{|c|c|c|c|c|}
\hline LOCALIDAD & $\begin{array}{c}\text { LO QUE } \\
\text { MONTAN } \\
\text { LOS APRECIOS }\end{array}$ & $\begin{array}{c}\text { REMATES Y } \\
\text { ALGUNAS } \\
\text { POSTURAS } \\
\text { QUE ESTÁN } \\
\text { HECHAS }\end{array}$ & $\begin{array}{c}\text { LO QUE } \\
\text { REMATARAN } \\
\text { LOS BIENES } \\
\text { APRECIADOS }\end{array}$ & $\begin{array}{c}\text { DEUDAS } \\
\text { QUE HAY } \\
\text { SOBRE } \\
\text { ELLOS }\end{array}$ \\
\hline Ocaña & 15.394.582 & 4.474 .569 & 484.126 & 6.884 .197 \\
\hline Santa Cruz de la Carca & 676.552 & 321.600 & 17.920 & 91.270 \\
\hline Puebla de Almaradil & 307.400 & 301.667 & 14.700 & 213.975 \\
\hline Villanueva de Cardete & 1.275 .634 & 995.766 & 14.700 & 213.975 \\
\hline Puebla de Don Fabrique & 223.626 & 219.298 & 900 & \\
\hline Villarubia & 925.480 & 438.600 & 13.550 & 206.672 \\
\hline Quintanar & 1.075 .170 & 995.518 & 9.070 & 170.960 \\
\hline Corral de Amaguer & 629.664 & 606.461 & 3.700 & 36.873 \\
\hline Villatovas & 1.078 .014 & 536.936 & 28.850 & 241.500 \\
\hline Dosbarrios & 521.160 & 257.465 & 8.820 & 56.396 \\
\hline Villa del Toboso & 1.627 .515 & 1.884 .870 & 6.220 & 500.000 \\
\hline Ontigola & 117.000 & 20.000 & 3.100 & 0 \\
\hline La Mota el Cuervo & 1.319 .230 & 898.489 & 18.350 & 52.000 \\
\hline La Cabeza & 30.000 & 46.480 & 0 & 0 \\
\hline Tarancón & 38.873 & 30.949 & 480 & 0 \\
\hline Socuellamos & 1.489 .985 & 476.811 & 39.356 & 0 \\
\hline Orcajo & 150.779 & 0 & 4.490 & 0 \\
\hline Villarejo de Salvanes & 1.110 .302 & 0 & 31.390 & 0 \\
\hline Villa Escusa de Arco & 460.831 & 0 & 38.138 & 0 \\
\hline Los Hinojosos & 155.900 & 0 & 5.300 & 0 \\
\hline Pedro Muñoz & 285.953 & 0 & 7.570 & 0 \\
\hline Fuentedueña & 313.500 & 0 & 9.470 & 102.000 \\
\hline La Fuente Pedro Nahorro & 10.614 & 0 & 300 & 0 \\
\hline TOTAL & 29.217.764 & 12.465 .464 & 748.730 & 8.562 .643 \\
\hline
\end{tabular}

"Según lo cual descontadas las deudas que hasta ahora han salido restaran que valen los bienes de estos 23 pueblos $20.665 .121 \mathrm{mrs}$, y que de ellos estaban rematados y vendidos $12.187 .974 \mathrm{mrs}$ con carga de $2.561 .815 \mathrm{mrs}$ de principal de censo y deudas que de ellos se han de bajar y bajado que quedaran horros para su Majestad 9.626.289 mrs". 


\section{Lugares de señorío}

\begin{tabular}{llr}
\hline LOCALIDAD & SEÑOR & TASACIÓN \\
\hline La Parrilla & Marqués de Cañete & 747.176 \\
Los Hinojos & Duque de Escalona & 28.050 \\
Belmonte & Duque de Escalona & 32.502 \\
Pliego & Conde de Pliego & 827.900 \\
Cardenote & Marqués de Moya & 13.464 \\
La Guardia & Francisco de Guardiola & 149.141 \\
Buenache & Juan de Alarcón & 311.494 \\
Cañete & Marqués de Cañete & 120.581 \\
Oreja & Marquesa de Cañete & 4.828 \\
Villamanrique de Tajo & Juan Laso de Castilla & 160.000 \\
\hline TOTAL & & 2.251 .136 \\
\hline
\end{tabular}

\section{COMISIÓN PARA EL JUEZ FrANCISCO DE BARRIONUEVO}

“Tuvo comisión en un principio para en principio para el Reyno de Murcia y obispado de Cartagena: y últimamente se le ha mandado vaya también a Alcaraz y su tierra y partido".

\section{Lugares de realengo}

"Los bienes que han dejado los moriscos en los pueblos de realengos de dicho Reyno y Obispado hasta ahora han salido sin los que están por salir en el Valle de Ricote y otras partes montan conforme a las tasaciones dellos sacados los censos y deudas: $38.088 .456 \mathrm{mrs}$. Hasta el 20 de julio de 1610 se habían vendido bienes por valor de $6.951 .833 \mathrm{mrs}$. En Alcaraz y su partido no están comprendidas en esta tasación, ya que en un principio era jurisdicción del Juez Hernando Salcedo".

\section{Lugares de señorío}

\begin{tabular}{llc}
\hline LOCALIDAD & SEÑOR & TASACIÓN \\
\hline Mula & Marqués de los Vélez & 1.417 .988 \\
Molina & Marqués de los Vélez & 41.514 \\
Librilla & Marqués de los Vélez & 118.610 \\
Alhama & Marqués de los Vélez & 257.200 \\
Cutillas & Juan Pérez Calvillo & 289.918 \\
Alcantarilla & Juan Uso de Mar & 162.118 \\
\hline TOTAL & & 2.287 .348 \\
\hline
\end{tabular}




\section{COMISIÓN PARA El JUEZ JuAN DíAZ DE SANTA CRUZ}

Se le mandó "a las ciudades de Sevilla y Écija y a todas las villas y lugares de la tierra de Écija y su partido".

\section{Lugares de realengo}

"Por la relaciones y papeles que embiado parece que los bienes que quedaron de los moriscos expelidos en la dicha ciudad de Sevilla y su término entrando en ellos las mejoras que les pertenecían en casas que tenían de por vidas de iglesias y obras pías de la dicha ciudad montaron según ventas o tasaciones que de los que estaban fechas descontados los censos perpetuos estimados a 3.000 (30 millones) y por las redimibles sus principales, $23.712 .628 \mathrm{mrs}$ y que dellos tenía vendidos hasta el 28 de septiembre 5.487.161 los 3.144.561 a pagar de contado y los 2.342 .600 al fiado y descontados de los de contado 905.856 de principal de censos perpetuos tasados a 3.000 y los de alquitar conforme a su fundación que daban al contado 2.238.705" ${ }^{\prime 30}$.

"Y que los bienes hasta el dicho día [marzo de 1611] imbetariados y tasados en la ciudad de Écija montavan conforme a la tasaciones $6.443 .438 \mathrm{mrs}$ de que se an de bajar los tributos que tuviesen que dice son muchos y que no estaban averiguados y que estava todo por vender el dicho día, según lo qual no se pude aquí sacar la suma que líquidamente quedara sacados las deudas.

Y no se an traído relaciones de los bienes que quedan en las ciudades de Cádiz, Gibraltar y Tarifa y villa de Prieto Real y lugares de sus jurisdicciones y lo que esto monta en ser" ${ }^{\prime \prime 31}$.

\section{COMISIÓN PARA EL JUEZ LICENCIADO PEDRO FERNÁNDEZ DE CASTROVERDE}

“Arzobispado de Sevilla en cuanto es obispo, excepto a la dicha ciudad y a Écija villas y lugares de su tierra, y después ansí se le dio comisión para la villa de Estepa y las demás villas y lugares de aquel estado".

\section{Lugares de realengo}

“Por las relaciones que han enviado parece que montan las tasaciones de los vienes que quedan en los lugares de realengos del distrito su comisión 9.345.138 mrs y aunque no declara si esto es habiendo bajado los censos y deudas se entiende que sí por haber enviado algunas relaciones con esta prevención.

\footnotetext{
30. AGS, CJH, 503-9-6.

31. AGS, CJH, 502-13-2.
} 
Y de los dichos 9.934.138 tiene vendidos al pie de 4.500.000 los 1.500 .000 de contado y los 3.000 .000 poco más o menos a plazos que no pasan de fin del año 1612 y sacados las costas pare abra ahora de contado 1.125.000 y los dichos 3.000.000 de obligaciones".

\section{Lugares de señorío}

“Los bienes que quedan en lugares de señorío del distrito desta comisión valen según las tasaciones otros 12.170.198 mrs que también se entiende ser horros de deudas por la razón dicha y son en esta materia".

\begin{tabular}{llr}
\hline LOCALIDAD & SEÑOR & TASACIÓN \\
\hline Osuna & Duque de Osuna & 4.290 .528 \\
Morón & Duque de Osuna & 1.192 .278 \\
El Arahal & Duque de Osuna & 171.768 \\
Marchena & Duque de Arcos & 1.373 .566 \\
Mairena & Duque de Arcos & 5.440 \\
Zahara & Duque de Arcos & 105.468 \\
Arcos & Duque de Arcos & 554.506 \\
Coronil & Duque de Alcalá & 59.092 \\
Cañete la Real & Duque de Alcalá & 63.206 \\
Bornos & Duque de Alcalá & 359.788 \\
Sanlúcar de Barrameda & Duque de Medina Sidonia & 1.792 .718 \\
Trebujena & Duque de Medina Sidonia & 112.948 \\
El Puerto de Santa María & Duque de Medinaceli & 235.620 \\
Villanueva del Río & Marqués de Villanueva del Río & 191.284 \\
Teba & Marqués de la Algaba & 276.760 \\
La Algaba & Marqués de la Algaba & $130.900^{32}$ \\
Olivares & Conde de Olivares & 68.068 \\
Fuentes & Marqués de Fuentes & 539.036 \\
Estepa & Marqués de Estepa & $265.166^{33}$ \\
La Roda & Marqués de Estepa & 44.880 \\
\hline & &
\end{tabular}

32. Que son de tres moriscos que se fueron. Quedan los demás.

33. Quedan moriscos con pleitos y no están contabilizados. 


\begin{tabular}{llr}
\hline LOCALIDAD & SEÑOR & TASACIÓN \\
\hline Cantillana & Juan Vicentelo $^{34}$ & 81.464 \\
Villaverde & Juan Vicentelo & 37.060 \\
Brenes & Juan Vicentelo & 14.960 \\
Rianzuela de Solís & Francisco de Solís ${ }^{35}$ & 92.854 \\
Benazuza & Francisco Duarte $^{36}$ & 110.840 \\
\hline TOTAL & & 12.170 .198 \\
\hline
\end{tabular}

\section{COMISIÓN PARA El JUEZ JUAN DE TOVAR BECERRA}

“Se le mandó fuesse al obispado de Jaén y adelantamiento de Cazorla y Villa de Quesada y lugares de su jurisdicción".

\section{Lugares de realengo}

"Por los papeles y relaciones que a embiado parece que la hacienda que a quedado en algunos lugares realengos y de ordenes de su comisión según las ventas que de algunas dellos tiene fechas y de los que no están vendidos según las tasaciones y quitadas las deudas que habían parecido valen 14.064.145 y no ha enviado relaciones de los pueblos siguientes:

Quesada, Albanches, Ubeda, Baeza, Valdepeñas, Porcuna, Pegalajara, Los Billares, La villa de la Mancha, Axona, Torre de Don Jimena, Fuente del Rey, Torre del Campo, Villargordo Menjibar, Cazadilla, Jamilena, Lupión, La Torre Perogil, Solera, Baños, El Lugar de Santiago, Cabra (jurisdicción de Ubeda), la mitad de los Ibros que es de realengo, Jarafe Cortijo. Y que de los dichos 14.064.145 había vendido hasta el 30 de agosto del año pasado [1610] 4.008.483 las 282.342 dellos de contado y los 3.726.141 restantes al fiado...".

\section{Lugares de señorío ${ }^{37}$}

"Por los papeles que envió el dicho Juan de Tovar Becerra parece que en el distrito de su comisión hay 42 villas y lugares de señorío y que en los 24 de-

34. Felipe III creará el condado de Cantillana ese mismo año de 1611, y el primer conde fue Juan Vicentelo de Leca y Corzo, siendo el segundo señor de Cantilla pues el primero fue Juan Antonio Vicentelo de Leca.

35. Marqués de Rianzuela.

36. Aunque no hay certeza pudo ser el presidente de la Casa de Contratación del Consejo de Indias.

37. CJH, 520. 
llos quedaron para su mag. bienes de los moriscos cuyo valor conforme a las tasaciones sin sacar dellos las deudas que tienen por no estar averiguadas es en esta manera".

\begin{tabular}{|c|c|c|}
\hline LOCALIDAD & SEÑORÍO & TASACIÓN \\
\hline Nolejo & Diego Maldonado & 33.000 \\
\hline Guelma & Duque de Alburquerque & 1.195 .380 \\
\hline Torres & Marqués de Camarasa & 249.500 \\
\hline Garcies & Pedro de Quesada & 839.122 \\
\hline Bedmar & Luisa de Mendoza & 1.460 .689 \\
\hline Jodar & Gonzalo Carvajal & 1.039 .760 \\
\hline Cazorla & Adelantado de Cazorla ${ }^{38}$ & 2.468 .410 \\
\hline Liruela & Adelantado de Cazorla & 610.700 \\
\hline Villa Carrillo & Adelantado de Cazorla & 748.900 \\
\hline Yznatoraf & Adelantado de Cazorla & 1.410 .352 \\
\hline Villanueva del Arzobispo & Adelantado de Cazorla & 476.300 \\
\hline Soriguela & Adelantado de Cazorla & 144.500 \\
\hline Peal de Becerro & Pedro de Quesada & 5.236 \\
\hline Escañuela & Conde de Villar & 53.300 \\
\hline Villar Don Pardo & Conde de Villar & 28.000 \\
\hline La Guardia & Marqués de la Guardia & 83.500 \\
\hline Javalquinto & Marqués de Benavides & 37.500 \\
\hline Bailén & Conde de Bailén & 2.485 .670 \\
\hline Las Navas & Conde de San Esteban & 885.300 \\
\hline Santiestevan del Puerto & Conde de San Esteban & 815.572 \\
\hline El Castellar & Conde de San Esteban & 900.796 \\
\hline Savotte & Marqués de Camarasa & 124.714 \\
\hline Alcaudete & Conde de Alcaudete & 3.100 .300 \\
\hline Mármol & Conde de Salazar & 41.400 \\
\hline TOTAL & & 19.237.903 \\
\hline
\end{tabular}

38. El Adelantamiento de Cazorla pertenecía al Arzobispado de Toledo, por lo que sus adelantados son los arzobispos, en este momento es Bernardo de Rojas y Sandoval (1599-1618). 
“Y que las 18 villas, lugares y cortijos restantes en las 6 dellas que son Jimena, Villa Palacios, Cotillas, Bien Servida, Rispal y Villaverde, no había habido morisco no hay bienes que no a enviado relación de si quedaron algunos bienes no de los que valen en las otras doce que son las siguientes".

\begin{tabular}{ll}
\hline Canena & Marqués de Camaraza \\
Jimena & Luisa de Mendoza \\
Belmes & Gonzalo de Carvajal \\
La Moraleda & Gonzalo de Carvajal \\
Torrebradilla & Gabriel de Córdoba \\
La mitad de Ibros & Conde de Santiestevan \\
Villafranca & Marqués de Priego \\
La Solera & Conde de Santiestevan \\
El Castillo de la Rejena & Marqués de Camaraza \\
El Castillo de Nilches & Rodrigo de Quesada \\
El cortijo de Tovaruela & Gonzalo de Carvajal \\
\hline
\end{tabular}

\section{Comisión PARa el juez Pedro Zapata del Mármol}

"Al dicho juez se le mandó fuese a todas las ciudades, villas y lugares del Reyno de Granada y la villa de Archidona y demás lugares de su tierra y jurisdicción".

\section{Lugares de realengo}

En la ciudad de Granada "Por relación que ha enviado el 30 de enero de 1611. Parece que monta la tasas de los bienes raíces de la ciudad de Granada 16.725.948 mrs con carga de 3.455.522 mrs de principal de censo alquilar y $50.702 \mathrm{mrs}$ y siete gallinas de censos perpetuos de que hasta ahora se han mostrado recaudo, y q monta todo lo ha vendido $7.910 .145 \mathrm{mrs}$, los $5.537 .375 \mathrm{mrs}$ de contado y los $2.423 .780 \mathrm{mrs}$ al fiado y que de arrendamientos y sembrados se han cobrado $315.695 \mathrm{mrs}$ se han pagado de réditos de censos a particulares y de salarios de juez y oficiales de su comisión 1.053.138 mrs, según lo cual hay en Granada 4.799.932 mrs de contado y en obligaciones los dichos 2.423.780 mrs y que restan por vender 9.521 .782 mrs con carga de 2.168.032 mrs de principal de censos redimibles y $25.091 \mathrm{mrs}$ de renta de censos perpetuos que valuados los dichos censos perpetuos a $30.000 \mathrm{mrs}$ del bajados estos y los redimibles de los dichos 9.521 .782 mrs quedan por valor de lo que esta vendido 6.601.021 mrs (lo que queda por vender en Granada). 
Tasado total es de 16.725.948.

Vendido de contado 4.799.932.

Vendido obligaciones: 2.432.078.

Por vender en Granada: 6.601.021".

En el reino de Granada "Y en cuanto a los demás lugares de realengo del Reyno de Granada en carta de 6 de julio de 1610 escribió que las personas que había enviado a traer los registros de los partidos de Guadix, Baza y Málaga le escribían que aunque había muchos moriscos no había salido ninguno y todos traían pleitos y tenían papeles por donde pretendían quedar y estaba aguardando que viniesen para enviar relación y lo mismo escribió en carta de 13 de julio y que las justicias tenían amparados los moriscos mientras duran sus pleitos, y que en Granada no estaba acabada la expulsión por que muchos los traen y algunos estaban remitidos al consejo Real/ y en carta de 9 de noviembre escribió que por haber muerto el corregidor de Granada se habían dejado de embarcar los moriscos que faltaban de salir así que aquella ciudad como del corregimiento y que las causas había ido/ orden para ello por el estado al presidente de aquella chancillería se había escusado/ y así no se puede dar aquí razón de lo que valdrán estos mas bienes que quedaran en realengo".

\section{Lugares de señorío}

\begin{tabular}{llc}
\hline LOCALIDAD & SEÑOR & TASACIÓN \\
\hline Archidona $^{39}$ & Duque de Osuna & 1.913 .093 \\
Vélez Rubio & Marqués de los Vélez & $341.968^{40}$ \\
Box & Marqués de los Vélez & 750.000 \\
\hline TOTAL & & 2.330 .061 \\
\hline
\end{tabular}

\section{Comisión para el juez Pedro Carranza de Armante}

"Al dicho se le mandó que fuese a todas las ciudades, villas y lugares del obispado de Córdoba".

39. “Los bienes que quedaron conforme a la tasa que dellos se hizo 2.139.375 mrs sobre los cuales hay censos que se declara en las relaciones que han venido si son perpetuos o alquitar y presuponiendo que sean de a 14 montara su principal 226.282 mrs según lo cual quedarían 1.913.093, pero se entiende habrá otras deudas sobre ellos que habían salido".

40. "Se tasaron los bienes y no hay declaradas si hay deudas que bajar dellos". 


\section{Lugares de realengo}

"Por las relaciones que ha enviado parece que la hacienda que quedó en Córdoba, Bujante, Montoro, Cañete, Belalcazar e Inojosa lugares de realengo de los moriscos así expelidos como de los por expeler que ha inventariado y enviado relación de ella junta 5.536.481, de la que han de sacar los censos que tienen sobre ella. Las Inquisiciones de Córdoba, Granada y otros y muchas deudas y demandas que estaban pendientes. Y que los censos presentados hasta el día que se envió las dichas relaciones sin las dichas inquisiciones que no lo han presentado y sin las dichas demandas dice montaran 861.991 restaran por valor entre tanto que no se disminuye con los demás censos y deudas 4.674.460 y así mismo falta por enviar razón de los valores de otros 2 lugares de realengos: Santaella y Almodovar del Río. Y de lo que en Córdoba se había vendido parece tendian en ser poder de los fieles lo siguiente".

\section{Al contado: $1.269 .573 \mathrm{mrs}$ \\ Al fiado: $\quad 1.217 .202 \mathrm{mrs}$}

\section{Lugares de señorío}

“Las haciendas en los lugares de señorío deste obispado según las tasas que ha enviado el juez monta a 47.524.744 que están metidos en esta suma lo de los moriscos que quedan por expeler que es 10.650.592, sin haber sacado las deudas que deben todos los dichos bienes, que las de los censos presentados ante el juez hasta el 14 de octubre de 1610 montan en 13.188.884 de mas de censos de las dichas inquisiciones que no las han presentado.

Según lo cual sacado los dichos 13.188.884 de censos quedan 34.335 .860 mrs".

\begin{tabular}{llrrr}
\hline LUGAR & SEÑOR & TASACIÓN & $\begin{array}{r}\text { DEUDAS/ } \\
\text { CENSOS }\end{array}$ & $\begin{array}{r}\text { LIBRE DE } \\
\text { CARGAS }\end{array}$ \\
\hline Pliego $^{41}$ & Marqués de Pliego & 31.600 .354 & 7.401 .762 & 24.198 .592 \\
Montilla & Marqués de Montilla & 404.500 & 203.00 & 201.500 \\
Aguilar & Marqués de Montilla & 641.133 & 329.743 & 311.390 \\
Montalbán & Marqués de Montilla & 164.224 & 0 & 164.224 \\
La Puente D. Gonzalo & Marqués de Montilla & 1.956 .869 & 755.250 & 1.201 .619 \\
Castro el Río & Marqués de Montilla & 434.926 & 146.600 & 293.326 \\
Villafranca & Marqués de Montilla & 42.000 & 0 & 42.000 \\
Carcabuey & Marqués de Montilla & 505.000 & 0 & 505.000 \\
\hline
\end{tabular}

41. Están incluido 8.643.051 de bienes de moriscos que quedan por expeler. Las deudas y censos también se incluyen de los que quedan por salir. 


\begin{tabular}{llrrr}
\hline LUGAR & SEÑOR & TASACIÓN & $\begin{array}{r}\text { DEUDAS/ } \\
\text { CENSOS }\end{array}$ & $\begin{array}{r}\text { LIBRE DE } \\
\text { CARGAS }\end{array}$ \\
\hline Cabra & Duque de Sesa & 4.328 .306 & 2.440 .752 & 1.887 .554 \\
Baena & 681.000 & 305.974 & 375.026 \\
Isnajar & Duque de Sesa & 481.375 & 270.167 & 211.208 \\
Rute & Duque de Sesa & 284.500 & 109.350 & 175.150 \\
Lucena $^{42}$ & Duque de Sesa & 2.700 .666 & 698.286 & 2.002 .380 \\
Palma $_{\text {Montemayor }}^{43}$ & Duque de Cardona & 599.088 & 0 & 599.088 \\
Herrera Núñez & Conde de Palma & 228.075 & 0 & 228.075 \\
Zuheros & Conde de Alcaudete & 39.850 & 0 & 39.850 \\
Luque & Sin referencia & 389.125 & 0 & 389.125 \\
Carpio & Sin referencia & 1.079 .950 & 528.000 & 551.950 \\
Adamuz & Pedro Banegas & 343.953 & 0 & 343.953 \\
Pedro Abad & Marqués del Carpio & 508.250 & 0 & 508.250 \\
\hline TOTAL & Marqués de Carpio & 106.600 & 0 & 106.600 \\
\hline
\end{tabular}

"Será menos si al final no se expelen los moriscos que quedan por expeler y que además no están incluidos los censos que sobre ellos tuviere la Inquisición y las demandas pendientes y las que salieren de nuevo".

\section{COMISIÓN PARA EL JuEZ LiCENCIAdo PEDRO DE LAS CUeVAS}

"Se le mando para que fuese a las ciudades, villas y lugares del Priorato de San Juan, Campo de Montiel y Calatrava, Ciudad Real y su vicaria, Talavera de la Reina con su tierra y lugares que hay desde allí a la Puebla de Alcocer y Siruela y tierra de Capilla".

\section{Lugares de realengo}

No ha enviado relación de los bienes argumentando que en muchos lugares no han salido. Para ello escribe varias cartas, la última es de 10 de diciembre.

42. Están incluidos 293.250 de los bienes de los moriscos que quedan por expeler. Los censos corresponden a total, tanto los expelidos como los quedan por salir.

43. Entran 128.125 de los moriscos que quedan por expeler.

44. Entran 6.800 moriscos por expeler.

45. Entran 206.448 de los moriscos que quedan por expeler. 


\section{Lugares de señorío}

No se han hecho averiguaciones exactas por lo que no se sabe los censos existentes, así que no están incluidos.

\begin{tabular}{llr}
\hline LOCALIDAD & SEÑOR & TASACIÓN \\
\hline Valdepeñas & Marqués de Santa Cruz & 1.595 .558 \\
Santa Cruz & Marqués de Santa Cruz & 189.368 \\
Valenzuela & Marqués de Zúñiga & 41.750 \\
Picón & Juan de Estrada & 187.550 \\
Alcazar, Madrijuelos, Cañas, & Priorato de San Juan & 5.500 .000 \\
Argamasilla y Consuegra & Arzobispado de Toledo & 691.021 \\
Talavera de la Reina ${ }^{46}$ & Marqués de Santa Cruz & No han salido \\
Del Viso & Conde de Salinas & No han salido \\
Villarubia & Arzobispo de Toledo & No han salido \\
Villafranca de la Puente & & 8.207 .247 \\
\hline TOTAL & & \\
\hline
\end{tabular}

Advierte que hay más lugares de señorío pero que no había moriscos.

\section{COMISIÓN PARA JUAN RODRÍGUEZ DAZA Y POR SU MUERTE A JUAN JERÓNIMO DE CONTRERAS}

"Al dicho juez se cometió que fuese a los obispados de Segovia y Ávila".

"Los bienes que se hallaron en las dichas 2 ciudades y en Arevalo, Olmedo, Ontiveros, Madrigal, Pajares, Burgos, Hondo y Maello que todos los pueblos realengos de los granadinos que hasta el fin de año pasado habían salido destas ciudades y villas porque los mudéjares y otros antiguos aun no han salido montan conforme a las ventas que de algunos están hechas y a las tasaciones de otros: 8.859 .796 con cargo de 34.869 de censos perpetuos y 1.628.799 de censo al quitar que hasta el 23 de enero de este año. Y de los dichos 8.859.796 están vendidos 2.484.404 los 1.753 .717 a pagar de contado y los 730.687 a plazos y de lo contado se han redimido algunos censos al quitar y en cargándose los compradores de la paga de otros y se han pagado trecenos y decenos de cen-

46. Se han descontado los censos perpetuos y 31 personas que habían quedado en la dicha villa que no están incluidas. 
sos perpetuos y otras costas y salarios de manera que a poco mas o menos habrá de contado en ser en Segovia como 500.000 y allí y en Ávila habrá en obligaciones las dichas 730.687.

En cuanto a los demás lugares de realengo de los dichos obispados en muchos dellos no hay moriscos y de los en que los hay no han venido las relaciones no están averiguados y por haber muerto el dicho Juan Rodríguez Daza en 16 de enero está nombrado en su lugar Jerónimo Contreras".

\section{Lugares de señorío}

\begin{tabular}{llr}
\hline LOCALIDAD & SEÑOR & TASACIÓN \\
\hline Coca & Francisco de Fonseca & 484.640 \\
Navas de Oro de Coca & Francisco de Fonseca & 72.400 \\
Cisla & Pedro de Zúñiga & 260.000 \\
Flores de Ávila & & No hay moriscos \\
Cuellar, Fuente Dueñas, Oropesa & & No están averiguados \\
y demás lugares de señorío & & 583.040 \\
\hline TOTAL & & \\
\hline
\end{tabular}

\section{COMISIÓN PARA EL JUEZ JUAN DE LUJÁN}

“Al dicho Juez se mando fuese a los obispados de Salamanca, Valladolid, Osma y toda la Castilla la Vieja excepto a lo que della entre en los obispados de Segovia y Ávila".

"A enviado relaciones de que la hacienda que queda en Palencia y Medina del Campo vale según tasaciones 2.775.636 sin declarar si esto es horro de censos y deudas. De la de Valladolid no ha enviado general de lo que montan las tasas, ni han acabado de salir los moriscos pero a enviado $q$ de ventas $y$ arrendamientos de los bienes que hasta ahora a podido vender y arrendar ${ }^{47}$. Han procedido de contado y a plazos pasados hasta fin de enero deste año 3.141.585 de los cuales se han pagado 1.364 .145 en redimir censos y pagar deudas de los dichos bienes y mas 434.400 de salarios y hasta de la comisión según lo cual a de haber de contado promptos en poder de los fieles $1.343 .040 \mathrm{mrs}$ en dinero y mas 3.832.562 en obligaciones que han procedido ansi de arrendamientos de algunos de los bienes de aquella ciudad que van corriendo, como de ventas dellos de los quedaron en Tordesillas que se entregaron a los fieles de

47. Olatz Villanueva da una cifra de 11.571.759 para Valladolid, Tordesillas y el lugar de Boecillo. 
Valladolid falta mucho por vender en aquella ciudad y de los demás lugares realengo de su distrito no ha enviado relaciones porque los mas moriscos que hay en Toro, Zamora, Ciudad Rodrigo, Osma y aquel contorno dice en cartra de 12 de enero son de los más antiguos y que han salido.

Al dicho Juez se mando fuese a los obispados de Salamanca, Valladolid, Osma y toda la Castilla la Vieja excepto a lo que della entre en los obispados de Segovia y Ávila".

\section{Lugares de señorío}

\begin{tabular}{llr}
\hline LOCALIDAD & SEÑOR & TASACIÓN \\
\hline Tudela & Duque de Lerma & 363.000 \\
Dueñas & Marqués de la Algaba & 726.633 \\
Portillo & Conde de Benavente & 15.300 \\
Castrejón & Conde de Ayala & 10.000 \\
Gumiel de Iziaques & Duque de Osuna & 9.000 \\
Berlanga & Marqués de Berlanga & 47.000 \\
Alba de Tormes & Duque de Alba & 38.000 \\
Peñaranda & Duque de Peñaranda & 130.000 \\
Castro de Membribe & Duque de Peñaranda & 14.000 \\
Benavente & Conde de Benavente & 300.000 \\
Villa Escusa & Encomienda de San Juan & 10.000 \\
Santiestevan de Gormaz & Duque de Escalona & Sin relación \\
(y Ayllón, y otros lugares de & & \\
señorío del distrito, no aparece \\
en la nueva relación)
\end{tabular}

\section{COMISIÓn PARA EL JuEZ Francisco NúÑeZ de Alarcón}

"Al dicho juez se le ordenó fuese a todas las ciudades villas y lugares de la provincia de Extremadura excepto a la villa de Hornachos".

48. Que si son de los antiguos podrán disponer de ellas.

49. Dice que los nobles no mandaron relación porque las haciendas de importancia son las de los mudéjares y que estos no han salido. Dice que valen 10.000 ducados pero como tengan informaciones de buenos cristianos podrán vender sus bienes raíces. 


\section{Lugares de realengo}

"Por las relaciones que ha enviado de los bienes de algunos moriscos que han salido de los dichos distritos, y de los colmenares y colmenas y frutos dellas que en el dejaron moriscos de los de Hornachos para que han montado los de que ha enviado relación a las tasaciones que dellos se hicieron y a las posturas de otras q por ser mayor que las tasaciones se ajustan mas a la verdad 6.254.122 horros de los censos y deudas que habían salido. Que no ha enviado relación de los bienes que han quedado en Llerena, Plasencia, Mérida, Hinojosa y otras muchas villas y lugares de su comisión por no haber salido los moriscos".

"Y que lo que ha vendido hasta ahora 3 de febrero deste año monta 3.274.292 mrs las 921.704 de contado y 2.361 .488 al fiado y que de los de contado están gastados en salarios y costas 323.540 se han de bajar ciertos prometidos: $9.821 \mathrm{mrs}$ por lo que quedan $2.352 .665 \mathrm{mrs}$.

\section{Lugares de señorío}

\begin{tabular}{lllr}
\hline LOCALIDAD & SEÑOR & DEUDAS/CENSOS & TASACIÓN \\
\hline Villa del Puerto & Juan de Vargas & & 85.750 \\
Medellín & Conde de Medellín & & $346.534^{50}$ \\
La Oliva & & 540.089 \\
La Oliva $^{51}$ & Duque de Feria & & 25.840 \\
Zafra & Duque de Feria & & 2.902 .924 \\
Almendral & Duque de Feria & & 649.566 \\
Salvatierra & Duque de Feria & & 97.988 \\
La Parra & Duque de Feria & & 48.110 \\
La Torre del Almendral & Duque de Feria & & 67.320 \\
Burguillos & Duque de Béjar & Descontados & 445.045 \\
Valverde & Duque de Béjar & Sin censos & 5.250 \\
Meajadas & Conde de Medellín & Descontados & 22.978 \\
Don Benito & Conde de Medellín & Sin censos & 93.714 \\
Guarena & Conde de Medellín & Descontados & 11.250 \\
La Villa de la Mancha & Conde de Medellín & Sin censos & 7.500 \\
Villanueva del Fresno & Marqués del Fresno & Sin censos & 104.856 \\
Villanueva de Barcarrota & Marqués del Fresno & Sin censos & 43.054 \\
\hline
\end{tabular}

50. 281.852 son en colmenares y colmenas y frutos que eran de los moriscos de Hornachos.

51. En el documento dice que "y porque hay dos villas deste nombre en esta provincia se duda si es igual". 


\begin{tabular}{lllr}
\hline LOCALIDAD & SEÑOR & DEUDAS/CENSOS & TASACIÓN \\
\hline Alconchel & Antonio de Meneses & Sin censos & 41.729 \\
La Higuera de Vargas & Teresa & Descontados & 8.552 \\
Abadia & Duque de Alba & 38.014 \\
Santibáñez & Duque de Alba & 8.976 \\
Vilorias & Duque de Alba & 5.236 \\
Aldea Nueva del Camino & Duque de Alba & 2.244 \\
Jarandilla & Conde de Oropesa & 135.000 \\
Olguera & Conde Osorno & 60.964 \\
Puerto de Baños & & 49.368 \\
La Villa Arroyo el Puerco & Marqués de Monte Mayor & & 14.960 \\
\hline TOTAL & Conde de Benavente & & 5.045 .446 \\
\hline
\end{tabular}

“La hacienda que quedó en todos los lugares de señorío del distrito de su comisión donde han quedado bienes de moriscos montan conforme a las relaciones que ha enviado 5.045.446 mrs. horros de los censos y deudas que hasta ahora han aparecido".

\section{PARTIDO DE LA COMISIÓN DEL CORREGIDOR DE ÁGREDA LiCENCIADO Diego CASTEllanos DE MAUdeS ${ }^{53}$}

Esta comisión se creó el 25 de febrero de 1611, y fue una comisión especial para la tasación de los bienes de moriscos en los lugares de señorío de la zona de Ágreda.

"El dicho corregidor no ha enviado relación del distrito de su comisión aunque por la instrucción que se le dio se le ordeno, y después aca se le han pedido diversas veces y porque informa Lazaro Roldan de Arraiga un comisario que tubo en ella parece que había en el dicho distrito los lugares de señorío que abajo se dirá y que en cada lugar había un cuanto a los bienes siguientes".

\begin{tabular}{llc}
\hline LOCALIDAD & SEÑOR & TASACIÓN \\
\hline Aguilar & Conde de Aguilar (señor de Cameros) & 0 \\
Cervera & Conde de Aguilar & 0 \\
\hline
\end{tabular}

52. No han salido los moriscos.

53. En lugar de Maudes puede ser Méndez.

54. Los moriscos tuvieron licencia para vender sus bienes. 


\begin{tabular}{|c|c|c|}
\hline LOCALIDAD & SEÑOR & TASACIÓN \\
\hline Nájera & Duque de Nájera & 150.000 \\
\hline Velorado & Condestable de Castilla ${ }^{55}$ & 0 \\
\hline Navarrete & Duque de Nájera & 0 \\
\hline Haro & Condestable $\mathrm{e}^{56}$ & 0 \\
\hline Iribiescas & Condestable $\mathrm{e}^{57}$ & 0 \\
\hline Medinaceli & Duque de Medinaceli ${ }^{58}$ & 0 \\
\hline Deza & Duque de Medinaceli ${ }^{59}$ & 0 \\
\hline Arcos & Duque de Medinaceli60 & 0 \\
\hline Armedo & Conde de Nieva ${ }^{61}$ & 0 \\
\hline Erleques (Eizeques) & Monasterio de Monjas $^{62}$ & 0 \\
\hline TOTAL & & 150.000 \\
\hline
\end{tabular}

“...y esto será más o menos según las relaciones que enviare este corregidor que serán mas ciertas. Y no se declara quales de los dichos lugares son solariegos porque el consejo satisfaçio a esto como se dice al principio desta relación".

\section{COMISIÓN PARA EL JUEZ LICENCIADO TOMÁS DE CARLEVAL}

Para la villa de Hornachos y su término.

"Por carta que escribió en 14 de abril de 1610 dijo que entra tanto que acaba de los inventarios y tasaciones había hecho un tanteo a poco más o menos de la hacienda que quedaba en aquel lugar". El total de la tasación se estimó en un principio en $45.862 .500 \mathrm{mrs}$.

55. No han salido.

56. Los moriscos tuvieron licencia para vender sus bienes.

57. Los moriscos tuvieron licencia para vender sus bienes.

58. Los moriscos tuvieron licencia para vender sus bienes.

59. Los moriscos tuvieron licencia para vender sus bienes.

60. Había pleitos entre la Inquisición y la duquesa de Medinaceli sobre los bienes diciendo ser lugar de solariego y cada parte los pretendía.

61. No habían salido los moriscos.

62. No habían salido los moriscos. 


\section{Resumen de las tasaciones}

\begin{tabular}{lcr}
\hline JUEZ & REALENGO & SEÑORÍO \\
\hline Hernández de Salcedo & 14.724 .441 & 29.130 .026 \\
Andrés de Aranda & 29.945 .368 & 2.251 .136 \\
Francisco Barrionuevo & 38.088 .456 & 2.287 .358 \\
P. Fernández de Castroverde & 9.345 .138 & 12.170 .198 \\
Juan Díaz de Santa Cruz & 30.156 .066 & \\
Juan Tovar Berrera & 14.064 .145 & 19.237 .903 \\
Pedro Zapata del Mármol & 13.219 .724 & 2.330 .061 \\
Carranza de Armante & 4.674 .490 & 34.335 .860 \\
Pedro de las Cuevas & No envió las tasaciones & 8.207 .247 \\
Jerónimo de Contreras & 8.859 .796 & 1.662 .933 \\
Juan de Luján & 7.951 .241 & 5.045 .446 \\
Francisco Núñez Alarcón & 6.254 .122 & 150.000 \\
Tomás de Carleval & 45.862 .500 & 117.391 .198 \\
Diego Castellanos Maudes & &
\end{tabular}

\section{A MODO DE CONCLUSIÓN}

De todos estos datos podemos concluir que el total de las tasaciones de los bienes raíces de los lugares de realengo ascendió a 223.145.487 mrs. y de los bienes en lugar de señorío a 117.408.210 mrs. Estas cifras deben de ser consideradas como mínimas, ya que habría que sumarles innumerables fraudes en ventas realizadas antes y después de las prohibiciones dadas el 14 de noviembre de 1609, por los que los moriscos no podían vender sus bienes raíces ${ }^{63}$. A lo que habría que añadir unas 70.000 libras de los bienes de los moriscos de Cataluña ${ }^{64}$, y el dinero recaudado por la monarquía por la venta de bienes raíces en Aragón cifrada, según un documento del Consejo y Junta de Hacienda, en 27.075.000 mrs. ${ }^{65}$.

63. En la actualidad estoy confeccionando un artículo donde se tratará este apartado.

64. AGS, Est. Leg. 229. La equivalencia en maravedíes sería aproximadamente unos 560.000.

65. En Aragón se arroja la cifra de 27.075 .000 mrs., "de lo procedido de bienes de los moriscos de Aragón se recogieron en poder del pagador de la gente de guerra del dicho reino". Sin que podamos precisar más hasta el momento. AGS, CJH, Leg. 509. 
Una de las fuentes de la recaudación más importante de las que contaba la monarquía era el servicio de millones, que en 1609 estaba previsto recaudar unos 2.000.000 de ducados, es decir unos 750.000.000 de maravedíes ${ }^{66}$. Entre el dinero ingresado por medio de las mitades y la venta de los bienes raíces confiscados se puede hablar de una cifra en torno a 500.000.000 de maravedíes ${ }^{67}$. Es una cifra nada desdeñable en un momento de gran necesidad económica. Aunque por el momento se desconoce la cuantía del coste de la expulsión (movilización de tropas, barcos, etc.), se puede deducir que gran parte de ello fue costeado por los moriscos a la hora de salir. En el caso de Sevilla se les impuso un tributo de 20 reales por persona, además del flete del navío, los cuales debían servir para "el coste de la expulsión" ${ }^{68}$. En conclusión se deduce que la expulsión fue desde un punto de vista económico rentable para las arcas de la monarquía a corto plazo, un desastre si este se analiza con perspectiva.

En teoría y según está expuesto en el bando de expulsión, la monarquía debía emplear lo recaudado de los bienes raíces en "el servicio de Dios". Aunque aún nos encontramos en una fase inicial de nuestra investigación podemos aportar algunos datos a este respecto. Los beneficios de las ventas de los bienes raíces de los moriscos de Andalucía se destinaron a las obras de fortificación de Larache, y parte de los bienes recaudados en Madrid y Guadalajara, concretamente 1.875.000 mrs., se emplearon en el pago de las obras del Alcázar y de la Casa de Campo ${ }^{69}$. También sabemos que el pueblo de Hornachos fue vendido íntegramente a los Fúcares como parte del pago de la deuda que la monarquía tenía contraída con los banqueros.

Como se ha podido constatar, la expulsión tuvo una vertiente económica que habría que analizar con el estudio de las fuentes documentales procedentes de las distintas contadurías, tarea imprescindible si realmente se desea avanzar en el estudio de la minoría. El volumen de este tipo de fuente unido y su carácter casi inédito auguran futuros trabajos que aportarán nuevas perspectivas y campos por explorar.

\section{RESUMEN}

La expulsión de los moriscos fue un proceso complejo, a pesar de los innumerables trabajos que se han realizado hasta el día de hoy aún quedan aspectos por dilucidar. La confiscación y venta de los bienes raíces de los mo-

\footnotetext{
66. AGS, Est. Leg. 626. Copia del billete original de Lerma al secretario Prada, 15 de enero de 1609. Son las previsiones de ingreso de la monarquía para dicho año, siendo el total de 4.687.350 ducados.

67. Cifra donde estarían comprendidos, los bienes raíces de los moriscos de Castilla, Aragón y lo recaudado por las mitades.

68. AGS, CMC, $3^{\circ}$ época, Leg. 2603.

69. AGS Dirección General del Tesoro (DGT) INV-24 517-3.
} 
riscos generó una inmensa documentación, cuyo estudio nos puede ayudar a comprender la vertiente económica de la expulsión, así como aspectos socioeconómicos de la minoría. En este artículo se presentan los primeros datos globales sobre la tasación de todos los bienes raíces de los moriscos en Castilla, Extremadura, Murcia y Andalucía, tanto en lugares de realengo como en lugares de señorío.

\section{ABSTRACT}

The expulsion of the Moriscos was a complex process that despite the countless works that have been made to this day, still remain aspects to be elucidated. The seizure and sale of real estate of the Moriscos created a vast documentation whose study can help us understand the economic side of the expulsion, and also those socioeconomic aspects of the minority. This article presents the first comprehensive data on the valuation of all real property of the Moriscos in Castile, Extremadura, Murcia and Andalusia, both in lordships and in places of royal dominion. 